\title{
A COMMON WEIGHTS MODEL FOR INVESTIGATING EFFICIENCY-BASED LEADERSHIP IN THE RUSSIAN BANKING INDUSTRY
}

\author{
Sajad Kazemi ${ }^{1}$ Madjid Tavana ${ }^{2,3, *}$ Mehdi Toloo ${ }^{4,5}$ Nikolay A. Zenkevich ${ }^{1}$
}

\begin{abstract}
In this race for productivity, the most successful leaders in the banking industry are those with high-efficiency and a competitive edge. Data envelopment analysis is one of the most widely used methods for measuring efficiency in organizations. In this study, we use the ideal point concept and propose a common weights model with fuzzy data and non-discretionary inputs. The proposed model considers environmental criteria with uncertain data to produce a full ranking of homogenous decision-making units. We use the proposed model to investigate the efficiency-based leaders in the Russian banking industry. The results show that the unidimensional and unilateral assessment of leading organizations solely according to corporate size is insufficient to characterize industry leaders effectively. In response, we recommend a multilevel, multicomponent, and multidisciplinary evaluation framework for a more reliable and realistic investigation of leadership at the network level of analysis.
\end{abstract}

Mathematics Subject Classification. 90-10, 90C11, 90C08, 90C30.

Received January 29, 2020. Accepted December 17, 2020.

\section{INTRODUCTION}

Globalization has converted the banking industry and, subsequently, the financial system into a vital sector of the economy [46]. Consequently, the efficiency of the banking industry has been a key driver of financial and economic development and growth $[41,90,96]$. Inefficient banks threaten the stability of the financial system, and banks are under constant pressure to increase their efficiency by adopting efficient banking practices, lowering their costs, improving productivity, and avoiding risky investments [8].

In this race for productivity, the most successful leaders in the banking industry are those with high profitability [29,92], visibility [21], and competitive advantage [9]. Consequently, according to the competitive dynamics $[43,72]$, and the neo-institutional theoretical perspectives $[25,56]$, organizations in similar situations tend to

Keywords. Data envelopment analysis, common weights, leadership, ideal point, fuzzy data, non-discretionary inputs, efficiency.

1 Graduate School of Management, Saint Petersburg State University, St. Petersburg, Russia.

2 Business Systems and Analytics Department, Distinguished Chair of Business Analytics, La Salle University, Philadelphia, PA 19141, USA.

3 Business Information Systems Department, Faculty of Business Administration and Economics, University of Paderborn, Paderborn, Germany.

4 Department of System Engineering, Faculty of Economics, Technical University of Ostrava, Ostrava, Czech Republic.

5 Department of Operations Management \& Business Statistics, College of Economics and Political Science, Sultan Qaboos University, Muscat, Oman.

${ }^{*}$ Corresponding author: tavana@lasalle.edu 
imitate the leader's structure, processes, and strategies $[48,49]$. Hence, studying the efficiency-based leadership among a set of competitive organizations such as banks is a critical task for managers who want to follow the leaders. In this regard, both parametric and non-parametric methods are widely used for efficiency analysis in the banking industry $[22,71,74]$. While parametric methods restrict the production function to a special parametric form before estimation them, non-parametric methods avoid a parametric production function and provide a clear understanding of the production possibility set [11].

One of the most applicable and popular non-parametric methods for performance measurement is the data envelopment analysis (DEA) method, which has been introduced by Charnes et al. [12]. The conventional DEA models consider three specific assumptions. First, they require precise input and output data. In contrast, the fuzzy and stochastic DEA models are designed to consider uncertain data in performance evaluation $[57,65]$. Second, primary models with homogeneous decision-making units (DMUs) have been developed using "exogenously fixed" or non-discretionary factors for different operating environments [7,37,64]. Third, initial models with the ability to divide DMUs into two groups of efficient and inefficient units without providing any additional information and ranking of the efficient DMUs have been proposed for performance evaluation $[4,16,36,50]$ in the form of common weights (CW) models [18]. We consider these three assumptions and propose a CW model for investigating efficiency-based leadership in the Russian banking industry.

The remainder of this paper is organized as follows. In Section 2, we present a review of the relevant literature review, followed by a description of the fuzzy CW model with non-discretionary inputs in Section 3. In Section 4, we present a case study to demonstrate the applicability of the proposed model. Conclusions and future research are provided in Section 6.

\section{LITERATURE REVIEW}

\subsection{Data envelopment analysis (DEA)}

DEA is a non-parametric fractional mathematical programming method for measuring and comparing the relative efficiency as a ratio of a weighted sum of the outputs to a weighted sum of the inputs among a set of homogeneous DMUs with numerous applications in airports, hospitals, universities, banks, technologies, etc. $[13,20,78,91]$. In the following, the CCR (Charnes, Cooper, and Rhodes) input-oriented model of DEA proposed by Charnes et al. [12] is presented as the central model for development in the literature.

\subsubsection{The CCR model}

Using the traditional denotations in DEA and according to the research of Charnes et al. [12], we assume that there are a set of $n$ DMUs and each $\mathrm{DMU}_{j},(j=1, \ldots, n)$ produces $s$ different outputs using $m$ different inputs which are denoted by $x_{i j},(i=1, \ldots, m)$ and $y_{r j},(r=1, \ldots, s)$, respectively. It is assumed that $x_{i j}$ and $y_{r j}$ are all positive. For any evaluated $\mathrm{DMU}_{j}$, the efficiency score $E$ can be calculated by the following CCR input-oriented multiplier model:

$$
\begin{array}{ll}
E_{o}=\max \sum_{r=1}^{s} u_{r} y_{r o} & \\
\text { s.t. } & \\
\sum_{r=1}^{s} u_{r} y_{r j}-\sum_{i=1}^{m} v_{i} x_{i j} \leq 0, \quad \forall j, \\
\sum_{i=1}^{m} v_{i} x_{i o}=1, & \forall r, \forall i \\
u_{r} \geq 0, v_{i} \geq 0, &
\end{array}
$$

where the decision variables $v_{i}$ and $u_{r}$ are the assigned weights for the $i$ th input and the $r$ th output, respectively. The efficiency score for $\mathrm{DMU}_{o}\left(E_{o}\right)$ is calculated as the weighted sum of its outputs, while the weighted sum of its inputs equals 1.

While the conventional DEA models such as CCR require accurate measurement of both inputs and outputs, crisp input and output data may not always be relevant in real-world situations. The observed values of the 
input and output data in real-world problems sometimes include missing data, judgment data, or predictive data, which are generally imprecise or vague. One way to deal with the uncertain data is the consideration of fuzzy numbers in developing DEA models [6,60]. Four general approaches have been recognized in the literature for developing fuzzy DEA models [27,90]. Here we will focus on the $\alpha$-level approach, which has been proposed by Saati et al. [65]. Although this approach is not computationally efficient, it is possibly the most popular method due to its linear computation for each $\alpha$ value [73]. In the following subsection, a particular case of fuzzy DEA with triangular fuzzy numbers for inputs and outputs has been proposed by Saati et al. [65] based on the CCR model.

\subsubsection{The fuzzy CCR model}

Saati et al. [65] define all inputs and outputs as triangular fuzzy numbers $\tilde{x}_{i j}=\left(x_{i j}^{l}, x_{i j}^{m}, x_{i j}^{u}\right)$ and $\tilde{y}_{r j}=\left(y_{r j}^{l}, y_{r j}^{m}, y_{r j}^{u}\right)$, respectively. The fuzzy CCR model using $\alpha$-level approach is formulated as model (2.2) and (2.3) by defining two interval variables, including $\hat{x}_{i j} \in\left[\alpha x_{i j}^{m}+(1-\alpha) x_{i j}^{l}, \alpha x_{i j}^{m}+(1-\alpha) x_{i j}^{u}\right]$ and $\hat{y}_{r j} \in\left[\alpha y_{r j}^{m}+(1-\alpha) y_{r j}^{l}, \alpha y_{r j}^{m}+(1-\alpha) y_{r j}^{u}\right]$ where $\alpha \in(0,1]$.

$$
\begin{array}{ll}
E_{o}=\max \sum_{r=1}^{s} u_{r} \hat{y}_{r o} & \\
\text { s.t. } & \forall j \\
\sum_{r=1}^{s} u_{r} \hat{y}_{r j}-\sum_{i=1}^{m} v_{i} \hat{x}_{i j} \leq 0, & \\
\sum_{i=1}^{m} v_{i} \hat{x}_{i o}=1, & \\
\alpha x_{i j}^{m}+(1-\alpha) x_{i j}^{l} \leq \hat{x}_{i j} \leq \alpha x_{i j}^{m}+(1-\alpha) x_{i j}^{u}, & \forall i, \forall j, \\
\alpha y_{r j}^{m}+(1-\alpha) y_{r j}^{l} \leq \hat{y}_{r j} \leq \alpha y_{r j}^{m}+(1-\alpha) y_{r j}^{u}, & \forall r, \forall j, \\
u_{r}, v_{i}, \hat{x}_{i j}, \hat{y}_{r j} \geq 0, & \forall r, \forall i, \forall j .
\end{array}
$$

The model includes $(n+1)(m+s)$ decision variables. Although model $(2.2)$ is a non-linear programming (NLP) model due to the existence of non-linear terms $v_{i} \hat{x}_{i j}$ and $u_{r} \hat{y}_{r j}$, it can be transformed into the following linear programming (LP) model (2.3) using two changes in variables $\dot{x}_{i j}=v_{i} \hat{x}_{i j}$ and $\dot{y}_{r j}=u_{r} \hat{y}_{r j}$, and substituting them in model (2.2):

$$
\begin{array}{ll}
E_{o}=\max \sum_{r=1}^{s} \dot{y}_{r o} & \\
\text { s.t. } & \\
\sum_{r=1}^{s} \dot{y}_{r j}-\sum_{i=1}^{m} \dot{x}_{i j} \leq 0, & \forall j, \\
\sum_{i=1}^{m} \dot{x}_{i o}=1, & \\
v_{i}\left(\alpha x_{i j}^{m}+(1-\alpha) x_{i j}^{l}\right) \leq \dot{x}_{i j} \leq v_{i}\left(\alpha x_{i j}^{m}+(1-\alpha) x_{i j}^{u}\right), & \forall i, \forall j, \\
u_{r}\left(\alpha y_{r j}^{m}+(1-\alpha) y_{r j}^{l}\right) \leq \dot{y}_{r j} \leq u_{r}\left(\alpha y_{r j}^{m}+(1-\alpha) y_{r j}^{u}\right), & \forall r, \forall j, \\
u_{r}, v_{i}, \dot{x}_{i j}, \dot{y}_{r j} \geq 0, & \forall r, \forall i, \forall j
\end{array}
$$

where $\dot{x}_{i j}$ and $\dot{y}_{r j}$ are decision variables used to convert the primary non-linear fuzzy model into a crisp parametric LP model while $\alpha \in(0,1]$ [62]. Accordingly, the model will provide an optimal solution for each $\alpha$. In this model, all evaluated DMUs must be homogeneous according to the original DEA's fundamental assumptions. However, in many real-world problems, environmental diversity may violate the presumption of homogenous units $[37,63]$. Ruggiero [63] has demonstrated that the consequence of not controlling the environmental variables results in biased estimation of technical efficiency. In response, researchers have focused on the "exogenously fixed" or "non-discretionary" factors in their models to meet this assumption (e.g., [7,35]). A CCR model with non-discretionary inputs proposed by Banker and Morey [7] is presented next to demonstrate the mathematical application of these inputs in the model. 


\subsubsection{The CCR model with non-discretionary inputs}

Homogeneity is a fundamental assumption for all basic DEA models [7]. According to the homogeneity assumption, all DMUs must agree to the following three conditions: (i) the DMUs should execute the same processes; (ii) their efficiency should be evaluated by the same input and output variables; and (iii) all DMUs operate within the same environment under the same conditions [99]. When environmental factors cause nonhomogeneity, they are considered in a single model as non-discretionary inputs. Therefore, different reference sets are defined to discriminate DMUs in different environments $[7,33,63]$. There is no generally accepted approach for using non-discretionary factors in DEA models. Therefore, this study considers the research of Banker and Morey [7], who proposed the CCR model by applying non-discretionary inputs $k\left(z_{k j}\right),(k=1, \ldots, t)$ for its simplicity and popularity as the following model (2.4):

$$
\begin{array}{ll}
E_{o}=\max \sum_{r=1}^{s} u_{r} y_{r o}-\sum_{k=1}^{t} w_{k} z_{k o}, & \\
\text { s.t. } & \\
\sum_{r=1}^{s} u_{r} y_{r j}-\sum_{k=1}^{t} w_{k} z_{k j}-\sum_{i=1}^{m} v_{i} x_{i j} \leq 0, & \forall j \\
\sum_{i=1}^{m} v_{i} x_{i o}=1, & \forall r, \forall i, \forall k, \\
u_{r}, v_{i}, w_{k} \geq \varepsilon, &
\end{array}
$$

where $\varepsilon$ is a small, non-negative number used to avoid ignoring factors in calculating efficiency for $\mathrm{DMU}_{o}[3]$.

This model can be extended to situations where some non-discretionary outputs are beyond the manager's discretionary controls. In this case, increasing output is not a meaningful target for managers while there are non-controllable outputs. In other words, managers are interested in estimating the maximum possible increase in the discretionary outputs with keeping the inputs and non-discretionary outputs at their current levels. Therefore, the output-oriented objective function of the CCR model describes this situation more realistically [7].

The above DEA models evaluate the relative efficiency with favorable weights for each DMU. These efficiency scores usually lie in $(0,1]$. While a ranking for inefficient DMUs is given using these models, they do not provide sufficient information about the efficient DMUs with an efficiency score of 1 . Researchers have solved this problem by using various methods (e.g., $[4,16,50,94])$. Among them, the CW models are more favorable and applicable according to the literature (e.g., $[15,28,50,76,79,86])$. In this research, we will use the CW model based on the ideal point method proposed by Sun et al. [75]. The prominent feature of this method compared to competing methods, is its feasibility feature [66].

\subsubsection{The $C W$ model with ideal point approach}

The CW models reduce the flexibility and the dispersion in the optimal weights assigned to the inputs and outputs by each DMU and make it possible to compare and rank the efficiency of all DMUs on the same basis $[42,86]$. In this study, we use the CW model based on the ideal point method proposed by Sun et al. [75], which provides a basic model for our final model development.

Definition 2.1. The (virtual) ideal DMU is a DMU that its inputs are at the minimum level, and its outputs are at the maximum level among all DMUs.

The ideal DMU is shown by IDMU $=(\underline{\boldsymbol{x}}, \overline{\boldsymbol{y}})$ where $\underline{\boldsymbol{x}}$ and $\overline{\boldsymbol{y}}$ respectively denote the inputs and outputs of the ideal unit, and $\underline{x}_{i}=\min \left\{x_{i j} \mid \forall j\right\},(\forall i)$ and $\bar{y}_{r}=\max \left\{y_{r j} \mid \forall j\right\},(\forall r)$. The CW model with ideal point method is developed next as model (2.5) based on the CCR model [44,75]: 


$$
\begin{array}{ll}
\theta=\min \sum_{j=1}^{n}\left[\sum_{i=1}^{m} v_{i}\left(x_{i j}-\underline{x}_{i}\right)\right]+\sum_{j=1}^{n}\left[\sum_{r=1}^{s} u_{r}\left(\bar{y}_{r}-y_{r j}\right)\right] & \\
\text { s.t. } & \forall j \\
\sum_{r=1}^{s} u_{r} y_{r j}-\sum_{i=1}^{m} v_{i} x_{i j} \leq 0, & \\
\sum_{i=1}^{m} v_{i} \underline{x}_{i}=1, & \forall i, \forall r, \\
\sum_{r=1}^{s} u_{r} \bar{y}_{r}=1, & \forall i, u_{r} \geq \varepsilon,
\end{array}
$$

where $(\boldsymbol{v}, \boldsymbol{u}) \in \mathbb{R}^{m+s}$ is the common set of weights and the constraints $\sum_{i=1}^{m} v_{i} \underline{x}_{i}=1$ and $\sum_{r=1}^{s} u_{r} \bar{y}_{r}=1$ ensure that the IDMU is efficient. The efficiency score of $\mathrm{DMU}_{j}$ is measured by $\frac{\sum_{r=1}^{s} u_{r}^{*} y_{r j}}{\sum_{i=1}^{m} v_{i}^{*} x_{i j}}$ for $j=1, \ldots, n$, which is less than or equal to one due to the first set of constraints.

In contrast to the conventional DEA models, which must be solved $n$ times, model (2.5) is solved one time for all units.

\section{PROposed MOdEL}

In this study, we propose a novel DEA model to overcome the shortfalls highlighted earlier and find a common set of weights in a fuzzy environment where the inputs $\tilde{x}_{i j}=\left(x_{i j}^{l}, x_{i j}^{m}, x_{i j}^{u}\right)$, non-discretionary inputs $\tilde{z}_{k j}=\left(z_{k j}^{l}, z_{k j}^{m}, z_{k j}^{u}\right)$, and outputs $\tilde{y}_{r j}=\left(y_{r j}^{l}, y_{r j}^{m}, y_{r j}^{u}\right)$ are triangular fuzzy numbers. To this aim, we define the fuzzy ideal DMU as FIDMU $=(\underline{\tilde{\boldsymbol{x}}}, \underline{\underline{z}}, \overline{\tilde{\boldsymbol{y}}})$ in which:

(a) $\underline{\tilde{x}}_{i}=\left(\underline{x}_{i}^{l}, \underline{x}_{i}^{m}, \underline{x}_{i}^{u}\right), \underline{x}_{i}^{b}=\min \left\{x_{i j}^{b} \mid \forall j\right\} \quad \forall i, \forall b \in\{l, m, u\}$.

(b) $\overline{\tilde{y}}_{r}=\left(\bar{y}_{r}^{l}, \bar{y}_{r}^{m}, \bar{y}_{r}^{u}\right), \bar{y}_{r}^{b}=\min \left\{y_{r j}^{b} \mid \forall j\right\} \quad \forall r, \forall b \in\{l, m, u\}$.

(c) $\overline{\tilde{z}}_{k}=\left(\underline{z}_{k}^{l}, \underline{z}_{k}^{m}, \underline{z}_{k}^{u}\right), \underline{z}_{k}^{b}=\min \left\{z_{k j}^{b} \mid \forall j\right\} \quad \forall k, \forall b \in\{l, m, u\}$.

Accordingly, the CW model with the ideal point method proposed by Sun et al. [75] is developed in a fuzzy environment by applying non-discretionary inputs in Models (2.3)-(2.5) and defining six interval variables, including $\hat{x}_{i j} \in\left[\alpha x_{i j}^{m}+(1-\alpha) x_{i j}^{l}, \alpha x_{i j}^{m}+(1-\alpha) x_{i j}^{u}\right], \underline{\hat{x}}_{i} \in\left[\alpha \underline{x}_{i}^{m}+(1-\alpha) \underline{x}_{i}^{l}, \alpha \underline{x}_{i}^{m}+(1-\alpha) \underline{x}_{i}^{u}\right]$, $\hat{z}_{k j} \in\left[\alpha z_{k j}^{m}+(1-\alpha) z_{k j}^{l}, \alpha z_{k j}^{m}+(1-\alpha) z_{k j}^{u}\right], \underline{\hat{z}}_{k} \in\left[\alpha \underline{z}_{k}^{m}+(1-\alpha) \underline{z}_{k}^{l}, \alpha \underline{z}_{k}^{m}+(1-\alpha) \underline{z}_{k}^{u}\right], \hat{y}_{r j} \in\left[y_{r j}^{m}+\right.$ $\left.(1-\alpha) y_{r j}^{l}, \alpha y_{r j}^{m}+(1-\alpha) y_{r j}^{u}\right]$, and $\overline{\hat{y}}_{r} \in\left[\alpha \bar{y}_{r}^{m}+(1-\alpha) \bar{y}_{r}^{l}, \alpha \bar{y}_{r}^{m}+(1-\alpha) \bar{y}_{r}^{u}\right]$ to propose the following NLP model:

$$
E_{\mathrm{IDMU}}^{*}(\alpha)=\min \sum_{j=1}^{n}\left[\sum_{i=1}^{m} v_{i}\left(\hat{x}_{i j}-\underline{\hat{x}}_{i}\right)+\sum_{k=1}^{t} w_{k}\left(\hat{z}_{k j}-\underline{\hat{z}}_{k}\right)+\sum_{r=1}^{s} u_{r}\left(\overline{\hat{y}}_{r}-\hat{y}_{r j}\right)\right]
$$

s.t.

$\sum_{r=1}^{s} u_{r} \hat{y}_{r j}-\sum_{i=1}^{m} v_{i} \hat{x}_{i j}-\sum_{k=1}^{t} w_{k} \hat{z}_{k j} \leq 0$

$\sum_{i=1}^{m} v_{i} \underline{\hat{x}}_{i}=1$,

$\sum_{r=1}^{s} u_{r} \overline{\hat{y}}_{r}-\sum_{k=1}^{t} w_{k} \hat{\underline{z}}_{k}=1$,

$\alpha x_{i j}^{m}+(1-\alpha) x_{i j}^{l} \leq \hat{x}_{i j} \leq \alpha x_{i j}^{m}+(1-\alpha) x_{i j}^{u}$,

$\forall i, \forall j$,

$\alpha \underline{x}_{i}^{m}+(1-\alpha) \underline{x}_{i}^{l} \leq \underline{\hat{x}}_{i} \leq \alpha \underline{x}_{i}^{m}+(1-\alpha) \underline{x}_{i}^{u}$, 


$$
\begin{array}{lr}
\alpha z_{k j}^{m}+(1-\alpha) z_{k j}^{l} \leq \hat{z}_{k j} \leq \alpha z_{k j}^{m}+(1-\alpha) z_{k j}^{u}, & \forall k, \forall j, \\
\alpha \underline{z}_{k}^{m}+(1-\alpha) \underline{z}_{k}^{l} \leq \underline{z}_{k} \leq \alpha \underline{z}_{k}^{m}+(1-\alpha) \underline{z}_{k}^{u}, & \forall k, \\
\alpha y_{r j}^{m}+(1-\alpha) y_{r j}^{l} \leq \hat{y}_{r j} \leq \alpha y_{r j}^{m}+(1-\alpha) y_{r j}^{u}, & \forall r, \forall j, \\
\alpha \bar{y}_{r}^{m}+(1-\alpha) \bar{y}_{r}^{l} \leq \overline{\hat{y}}_{r} \leq \alpha \bar{y}_{r}^{m}+(1-\alpha) \bar{y}_{r}^{u}, & \forall r, \\
v_{i}, u_{r}, w_{k} \geq \varepsilon, & \forall i, \forall r, \forall k, \\
\hat{x}_{i j}, \underline{\hat{x}}_{i}, \hat{z}_{k j}, \hat{z}_{k}, \hat{y}_{r j}, \overline{\hat{y}}_{r} \geq 0, & \forall i, \forall r, \forall k, \forall j .
\end{array}
$$

The NP model $(3.2)$ has $(n+2)(m+s+t)$ decision variables. We use six variable changes, including $\dot{x}_{i j}=$ $v_{i} \hat{x}_{i j}, \underline{\dot{x}}_{i}=v_{i} \underline{\hat{x}}_{i}, \dot{z}_{k j}=w_{k} \hat{z}_{k j}, \underline{\dot{z}}_{k}=w_{k} \hat{\underline{z}}_{k}, \dot{y}_{r j}=u_{i} \hat{y}_{r j}$, and $\bar{y}_{k}=u_{r} \overline{\hat{y}}_{r}$ to formulate the following linearized model:

$$
\begin{array}{ll}
E_{\mathrm{IDMU}}^{*}(\alpha)=\min \sum_{j=1}^{n}\left[\sum_{i=1}^{m}\left(\dot{x}_{i j}-\underline{\dot{x}}_{i}\right)+\sum_{k=1}^{t}\left(\dot{z}_{k j}-\underline{\dot{z}}_{k}\right)+\sum_{r=1}^{s}\left(\overline{\dot{y}}_{r}-\dot{y}_{r j}\right)\right] & \\
\text { s.t. } & \forall j, \\
\sum_{r=1}^{s} \dot{y}_{r j}-\sum_{i=1}^{m} \dot{x}_{i j}-\sum_{k=1}^{t} \dot{z}_{k j} \leq 0, & \\
\sum_{i=1}^{m} \underline{\dot{x}}_{i}=1, & \\
\sum_{r=1}^{s} \overline{\dot{y}}_{r}-\sum_{k=1}^{t} \underline{\dot{z}}_{k}=1, & \forall i, \forall j, \\
v_{i}\left(\alpha x_{i j}^{m}+(1-\alpha) x_{i j}^{l}\right) \leq \dot{x}_{i j} \leq v_{i}\left(\alpha x_{i j}^{m}+(1-\alpha) x_{i j}^{u}\right) & \forall i, \\
v_{i}\left(\alpha \underline{x}_{i}^{m}+(1-\alpha) \underline{x}_{i}^{l}\right) \leq \underline{x}_{i} \leq v_{i}\left(\alpha \underline{x}_{i}^{m}+(1-\alpha) \underline{x}_{i}^{u}\right), & \forall k, \forall j, \\
w_{k}\left(\alpha z_{k j}^{m}+(1-\alpha) z_{k j}^{l}\right) \leq \dot{z}_{k j} \leq w_{k}\left(\alpha z_{k j}^{m}+(1-\alpha) z_{k j}^{u}\right) & \forall k, \\
w_{k}\left(\alpha \underline{z}_{k}^{m}+(1-\alpha) \underline{z}_{k}^{l}\right) \leq \dot{\dot{z}}_{k} \leq w_{k}\left(\alpha \underline{z}_{k}^{m}+(1-\alpha) \underline{z}_{k}^{u}\right), & \forall r, \forall j, \\
u_{r}\left(\alpha y_{r j}^{m}+(1-\alpha) y_{r j}^{l}\right) \leq \dot{y}_{r j} \leq u_{r}\left(\alpha y_{r j}^{m}+(1-\alpha) y_{r j}^{u}\right) & \forall r, \\
u_{r}\left(\alpha \bar{y}_{r}^{m}+(1-\alpha) \bar{y}_{r}^{l}\right) \leq \overline{\dot{y}}_{r} \leq u_{r}\left(\alpha \bar{y}_{r}^{m}+(1-\alpha) \bar{y}_{r}^{u}\right) & \forall i, \forall r, \forall k, \\
v_{i}, u_{r}, w_{k} \geq \varepsilon, & \forall i, \forall r, \forall k, \forall j . \\
\dot{x}_{i j}, \underline{\dot{x}}_{i}, \dot{z}_{k j}, \underline{\dot{z}}_{k}, \dot{y}_{r j}, \overline{\dot{y}}_{r} \geq 0, &
\end{array}
$$

It is evident that in this model, all DMUs consider the IDMU as the reference object. In other words, the IDMU must take the efficiency value of one, and other DMUs are compared to the IDMU for efficiency calculation in a fuzzy environment.

This model is now a crisp parametric LP problem and provides an optimal solution table for different $\alpha$ values, $\alpha \in(0,1]$. The model possesses $(n+2)(m+s+t)$ decision variables and $(2 n+3)(m+s+t)+(n+2)$ constraints. Accordingly, if $\left(\boldsymbol{v}, \boldsymbol{u}, \boldsymbol{w}, \dot{\boldsymbol{x}}^{*}, \dot{\boldsymbol{y}}^{*}, \dot{\boldsymbol{z}}^{*}\right)$ is the optimal solution for model (3.3), then, we have $E_{j}^{* \alpha}=$ $\frac{\sum_{r=1}^{s} \dot{y}_{r j}^{*}-\sum_{k=1}^{t} \dot{z}_{k j}^{*}}{\sum_{i=1}^{m} \dot{x}_{i j}^{*}} . E_{j}^{* \alpha}$ is $\alpha$-efficiency score of $\mathrm{DMU}_{j}$ and the value of alpha affects efficiency scores. Also, according to model (3.3), the value of epsilon is important for its impact on the calculated weights of inputs and outputs. Note that an unsuitable value for the epsilon may lead to infeasibility [3,67]. In addition, its optimal value to reach maximum weights is another problem that needs further investigation.

Definition 3.1. $\mathrm{DMU}_{j}$ is said to be efficient at given $\alpha \in(0,1]$ if $E_{j}^{* \alpha}=1$.

Theorem 3.2. $E_{j}^{* \alpha_{2}} \leq E_{j}^{* \alpha_{1}}$ for $\alpha_{1} \leq \alpha_{2}$.

Proof. Let $S(\alpha)$ be the feasible region of the model (3.3) for a given $\alpha$. It is easy to verify that $S\left(\alpha_{2}\right) \subseteq S\left(\alpha_{1}\right)$. This fact that model (3.3) is a minimization problem that completes the proof.

The proposed model has several innovative features. Our model: 
(1) provides investigators with the opportunity to address three potential concerns collectively. The first concern is uncertainty and fuzzy variables. The second concern is related to the conventional DEA limitation of not providing sufficient information for evaluating and ranking the efficient DMUs. Finally, the third concern is the homogeneity of the DMUs as a central premise in DEA modeling.

(2) provides the leadership literature with a quantitative model for measuring leadership from an efficiency perspective, which has been emphasized in previous studies [19,30,47,97]. This characteristic of leadership illustrates the fact that an organization with a higher leadership index is more efficient and performs better than competing organizations [53,61]. As a result, these high-performing organizations become role models for other competitors $[29,48]$.

Finally, we suggest the following model (3.4) for finding a suitable value for the epsilon in model (3.3):

$$
\begin{array}{ll}
\varepsilon^{*}(\alpha)=\max \varepsilon & \\
\text { s.t. } & \\
\sum_{r=1}^{s} \dot{y}_{r j}-\sum_{i=1}^{m} \dot{x}_{i j}-\sum_{k=1}^{t} \dot{z}_{k j} \leq 0, & \forall j, \\
\sum_{i=1}^{m} \underline{x}_{i}=1, & \\
\sum_{r=1}^{s} \dot{y}_{r}-\sum_{k=1}^{t} \dot{\underline{z}}_{k}=1, & \\
v_{i}\left(\alpha x_{i j}^{m}+(1-\alpha) x_{i j}^{l}\right) \leq \dot{x}_{i j} \leq v_{i}\left(\alpha x_{i j}^{m}+(1-\alpha) x_{i j}^{u}\right) & \forall i, \forall j, \\
v_{i}\left(\alpha \dot{\dot{x}}_{i}^{m}+(1-\alpha) \underline{\dot{x}}_{i}^{l}\right) \leq \dot{x}_{i} \leq v_{i}\left(\alpha \underline{\dot{x}}_{i}^{m}+(1-\alpha) \underline{\dot{x}}_{i}^{u}\right), & \forall i, \\
w_{k}\left(\alpha z_{k j}^{m}+(1-\alpha) z_{k j}^{l}\right) \leq \dot{z}_{k j} \leq w_{k}\left(\alpha z_{k j}^{m}+(1-\alpha) z_{k j}^{u}\right) & \forall k, \forall j, \\
w_{k}\left(\alpha \dot{z}_{k}^{m}+(1-\alpha) \dot{\dot{z}}_{k}^{l}\right) \leq \dot{\dot{z}}_{k} \leq w_{k}\left(\alpha \dot{\dot{z}}_{k}^{m}+(1-\alpha) \dot{\dot{z}}_{k}^{u}\right), & \forall k, \\
u_{r}\left(\alpha y_{r j}^{m}+(1-\alpha) y_{r j}^{l}\right) \leq \dot{y}_{r j} \leq u_{r}\left(\alpha y_{r j}^{m}+(1-\alpha) y_{r j}^{u}\right) & \forall r, \forall j, \\
u_{r}\left(\alpha \dot{y}_{r}^{m}+(1-\alpha) \dot{y}_{r}^{l}\right) \leq \dot{y}_{r} \leq u_{r}\left(\alpha \dot{y}_{r}^{m}+(1-\alpha) \dot{y}_{r}^{u}\right) & \forall r, \\
\varepsilon-v_{i} \leq 0, & \forall i, \\
\varepsilon-u_{r} \leq 0, & \forall r, \\
\varepsilon-w_{k} \leq 0, & \forall k, \\
\varepsilon \geq 0 & \forall i, \forall r, \forall \\
\underline{\dot{z}}_{k}, \dot{y}_{r j}, \overline{\dot{y}}_{r} \geq 0, &
\end{array}
$$

where $\varepsilon$ is a decision variable. This parametric LP model presents the maximum epsilon $\left(\varepsilon^{*}\right)$ which applies to model (3.3) and all other values higher than $\varepsilon^{*}$ cause infeasible results.

Choosing a suitable value for $\varepsilon$ is a challenging problem in DEA (see $[80,81]$ ). The value of $\varepsilon$ selected in the epsilon-based DEA model influences the size of multipliers. In other words, different values of $\varepsilon$ may lead to various efficiency assessments. Cook et al. [17] explained that letting $\varepsilon=\varepsilon^{*}$, results in an identical assessment and, more importantly, the resulting DEA model has a sharper discriminating power.

Theorem 3.3. Model (3.4) is always feasible.

Proof. Let $\dot{y}_{r j}^{0}=\frac{1}{s} \forall r, \forall j, \dot{x}_{i j}^{0}=\frac{1}{m} \forall i, \forall j, \dot{x}_{k j}^{0}=\frac{1}{t} \forall k, \forall j, \underline{\dot{x}}_{i}^{0}=\frac{1}{m} \forall i, \overline{\dot{y}}_{r}^{0}=\frac{1}{s} \forall r, \underline{\dot{x}}_{k}^{0}=\frac{1}{t} \forall k, v_{i}^{0} \in$ $\left[\frac{1}{\alpha \underline{\dot{x}}_{i}^{m}+(1-\alpha) \underline{\dot{x}}_{i}^{u}}, \frac{1}{\alpha \underline{\dot{x}}_{i}^{m}+(1-\alpha) \dot{\dot{x}}_{i}^{l}}\right] \forall i, w_{k}^{0} \in\left[\frac{1}{\alpha \underline{\dot{\dot{z}}}_{k}^{m}+(1-\alpha) \underline{\dot{\dot{z}}}_{k}^{u}}, \frac{1}{\alpha \underline{\dot{z}}_{k}^{m}+(1-\alpha) \dot{\underline{x}}_{k}^{l}}\right] \forall k, u_{r}^{0} \in\left[\frac{1}{\alpha \bar{y}_{r}^{m}+(1-\alpha) \bar{y}_{r}^{u}}, \frac{1}{\alpha \bar{y}_{r}^{m}+(1-\alpha) \bar{y}_{r}^{l}}\right] \forall r$, and $\varepsilon=\min \left\{v_{i}^{0}, w_{k}^{0}, u_{r}^{0}, \forall i, \forall k, \forall r\right\}$. Since $\alpha \underline{\dot{x}}^{m}{ }^{m}+(1-\alpha){\underline{\dot{x}_{i}}}^{u} \leq \alpha x_{i j}^{m}+(1-\alpha) x_{i j}^{u}$ and $\alpha{\underline{\dot{x}_{i}}}^{m}+(1-\alpha) \underline{\dot{x}}_{i}^{l} \leq$ $\alpha x_{i j}^{m}+(1-\alpha) x_{i j}^{l} \forall i, \forall j$ it is easy to verify that:

$$
v_{i}^{0}\left(\alpha x_{i j}^{m}+(1-\alpha) x_{i j}^{l}\right) \leq \frac{1}{m} \leq v_{i}^{0}\left(\alpha x_{i j}^{m}+(1-\alpha) x_{i j}^{u}\right), \quad \forall i, \forall j
$$


and

$$
v_{i}^{0}\left(\alpha \underline{\dot{x}}_{i}^{m}+(1-\alpha) \underline{\dot{x}}_{i}^{l}\right) \leq \frac{1}{m} \leq v_{i}^{0}\left(\alpha \underline{\dot{x}}_{i}^{m}+(1-\alpha) \underline{\dot{x}}_{i}^{u}\right), \quad \forall i .
$$

Analogously, we obtain:

$$
\begin{array}{lll}
w_{k}^{0}\left(\alpha z_{k j}^{m}+(1-\alpha) z_{k j}^{l}\right) \leq \frac{1}{t} \leq w_{k}^{0}\left(\alpha z_{k j}^{m}+(1-\alpha) z_{k j}^{u}\right), & \forall k, \forall j, \\
w_{k}^{0}\left(\alpha \underline{\dot{z}}_{k}^{m}+(1-\alpha) \underline{\dot{z}}_{k}^{l}\right) \leq \frac{1}{t} \leq w_{k}^{0}\left(\alpha \underline{\dot{z}}_{k}^{m}+(1-\alpha) \dot{\underline{z}}_{k j}^{u}\right), & \forall k, \\
u_{r}^{0}\left(\alpha y_{r j}^{m}+(1-\alpha) y_{r j}^{l}\right) \leq \frac{1}{s} \leq u_{r}^{0}\left(\alpha y_{r j}^{m}+(1-\alpha) y_{r j}^{l}\right), & \forall r, \forall j, \\
u_{r}^{0}\left(\alpha \bar{y}_{r}^{m}+(1-\alpha) \bar{y}_{r}^{l}\right) \leq \frac{1}{s} \leq u_{r}^{0}\left(\alpha \bar{y}_{r}^{m}+(1-\alpha) \overline{\dot{y}}_{r}^{u}\right), & \forall r
\end{array}
$$

Hence, the vector $\left(\varepsilon^{0}, \boldsymbol{v}^{0}, \boldsymbol{u}^{0}, \boldsymbol{w}^{0}, \dot{\boldsymbol{x}}^{0}, \dot{\boldsymbol{y}}^{0}, \dot{\boldsymbol{z}}^{0}, \underline{\dot{\boldsymbol{x}}}, \overline{\dot{\boldsymbol{y}}}, \underline{\dot{\boldsymbol{z}}}\right)$ is a feasible solution for model (3.4). This completes the proof.

Theorem 3.4. $\varepsilon^{*} \in(0, \infty)$.

Theorem 3.5. model (3.3) is feasible for $\varepsilon=\varepsilon^{*}$ (see [82]).

\section{Case Study}

In this section, we study the efficiency-based leadership in 20 independent banks ${ }^{1}$ in the Russian Federation using the method proposed in this study. The Russian banking sector has experienced considerable disorder in a highly centralized economy with the collapse of the Soviet Union. Russian banking system operates in an adverse economic environment and is dominated by large state-owned banks, which are highly fragmented and free of financial repression. The most significant feature of the modern Russian banking system is that the rules and regulations do not apply to all banks equally [45,54,95]. Among emerging and transition economies, the Russian banking industry has been rarely studied for performance management and efficiency.

\subsection{Measurement inputs and outputs}

DEA does not provide any guidelines for selecting input and output variables. Many researchers have suggested regression analysis and principal component analysis for selecting input and output variables. Deposit is a factor widely used for DEA applications in the banking industry with a dual role $[31,77,88]$. There are three approaches for designating deposits as inputs, outputs, or both (dual role). These approaches include the production approach with the aim of deposit producing, intermediation approach with the aim of profit earning, and intermediate product approach with both aims through two processes [31,62]. Appropriate inputs are those variables that managers would like to minimize, and appropriate outputs are those with the maximizing purpose [59]. We found employees, fixed assets, and interest expenses are regularly defined as input variables (e.g., $[34,58])$ while loans and incomes are regularly defined as output variables (e.g., $[24,40])$. We performed a comprehensive review of the recent DEA applications in the banking industry presented in Table 1 to select the most suitable input and output variables for our study. We chose three discretionary inputs $\left(x_{1}\right.$ : number of branches, $x_{2}$ : interest expense, and $x_{3}$ : total expenses); two outputs ( $y_{1}$ : net profit and $y_{2}$ : total assets as the ultimate outputs); and one non-discretionary input $\left(z_{1}\right.$ : branch density, which is defined as the number of branches per square kilometer and is an indicator of the space dimension for each national market). $z_{1}$ represents the availability of banking services for clients [52].

\footnotetext{
1 The names are changed to protect the anonymity of the banks.
} 
TABLE 1. Most recent DEA publications banking.

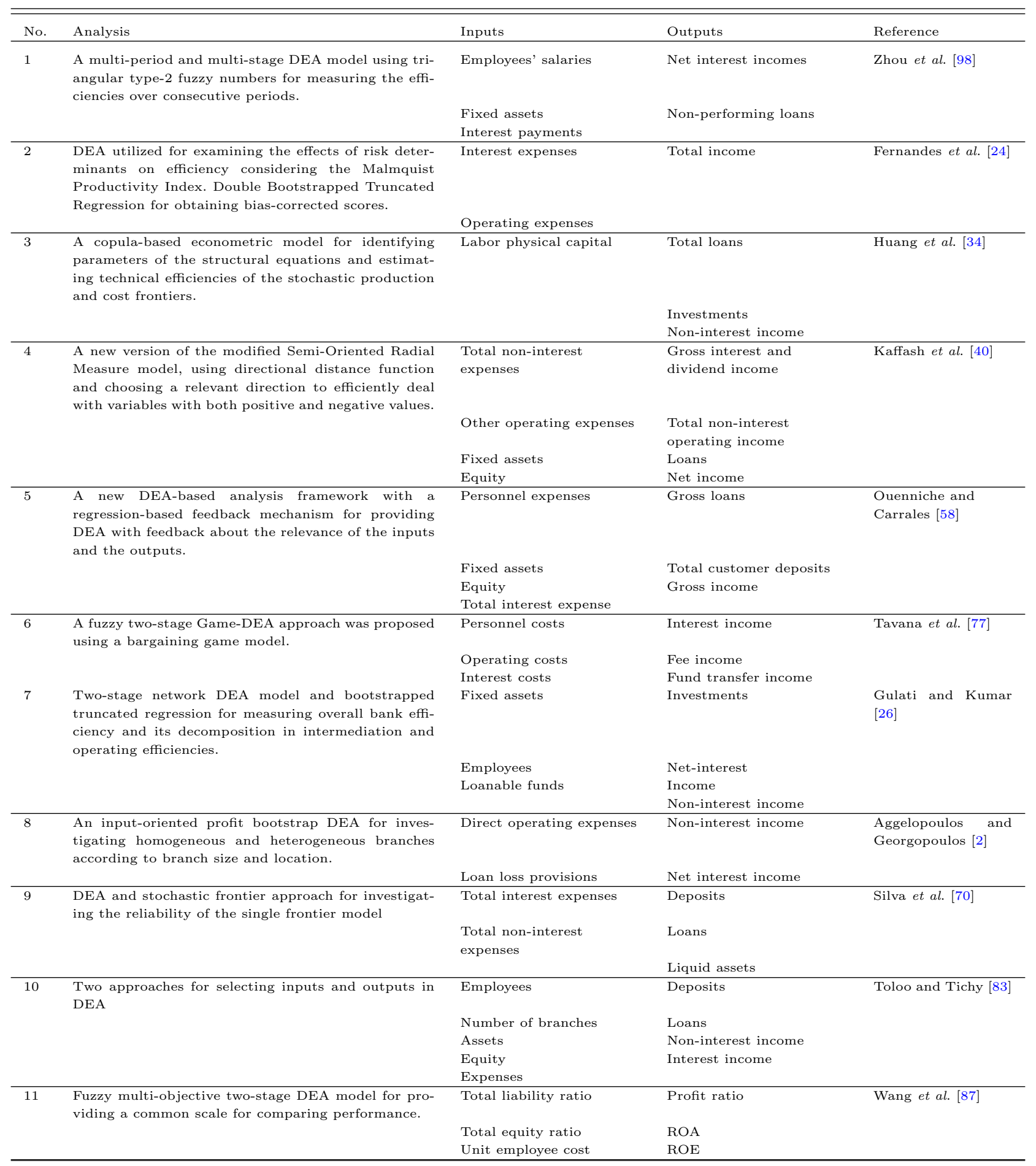


TABLE 1. Continued.

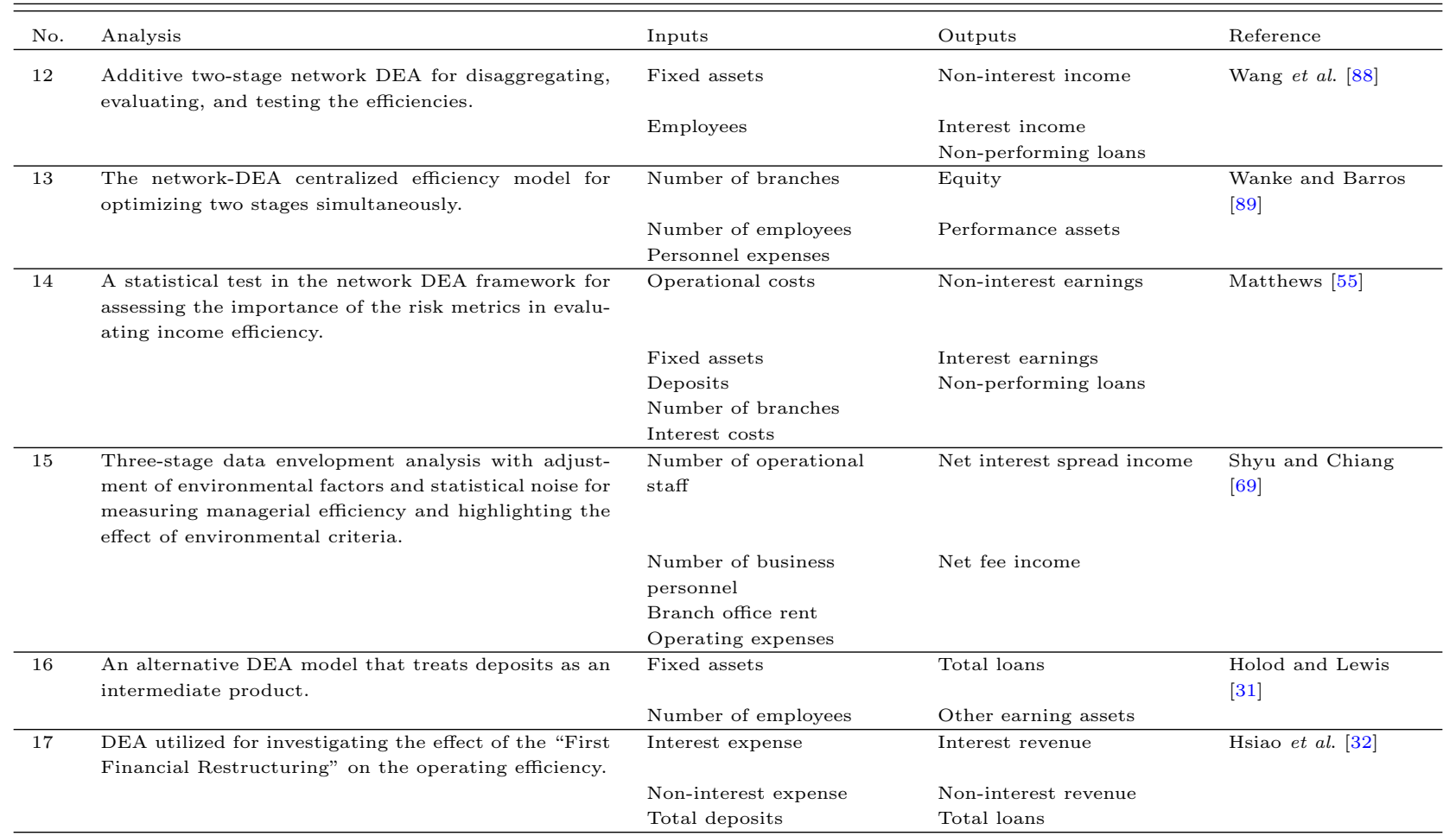

\subsection{Data collection}

We developed a database using the 2018 financial statements of the 20 banks selected for this study. In addition, we used the annual reports from the SPARK database, provided by the Interfax news agency and the Central Bank of the Russian (CBR) Federation. Russia is ideal for this study because of its largest market among the Commonwealth of Independent States countries with bank-based economies. We used the websites of the Russian banks and the CBR site to collect data on banks in this study. While the collected data were in crisp form, there were some uncertainties concerning the accuracy of the data. We also needed to consider the problem of income smoothing in financial statements [10]. In response, we decided to use fuzzy sets [93] to incorporate these uncertainties and ambiguities into our model [62]. We used triangular fuzzy numbers $\left(a^{l}, a^{m}, a^{u}\right)$ to represent the uncertainties and vagueness in our data [14]. Accordingly, the collected crisp was converted into triangular fuzzy data through the following steps [62]:

(1) Considering crisp data as $a^{m}$.

(2) $a^{l}$ is equal to $a^{m}-1 \% a^{m}$.

(3) $a^{u}$ is equal to $a^{m}+0.01 \% a^{m}$.

The fuzzy input and output data for the Russian banks considered in this study are presented in Table 2 .

\section{RESUlts AND DISCUSSION}

We used model (3.3) to calculate the efficiencies of 20 banks (DMUs) and normalized the results. The normalization of the efficiency scores is intended to produce efficiencies between 0 and 1 with at least one efficient unit $[39,85]$. We used the GAMS program with different $\alpha$ values and an epsilon value of $10^{-7}$. We selected 
EFFICIENCY-BASED LEADERSHIP ASSESSMENT

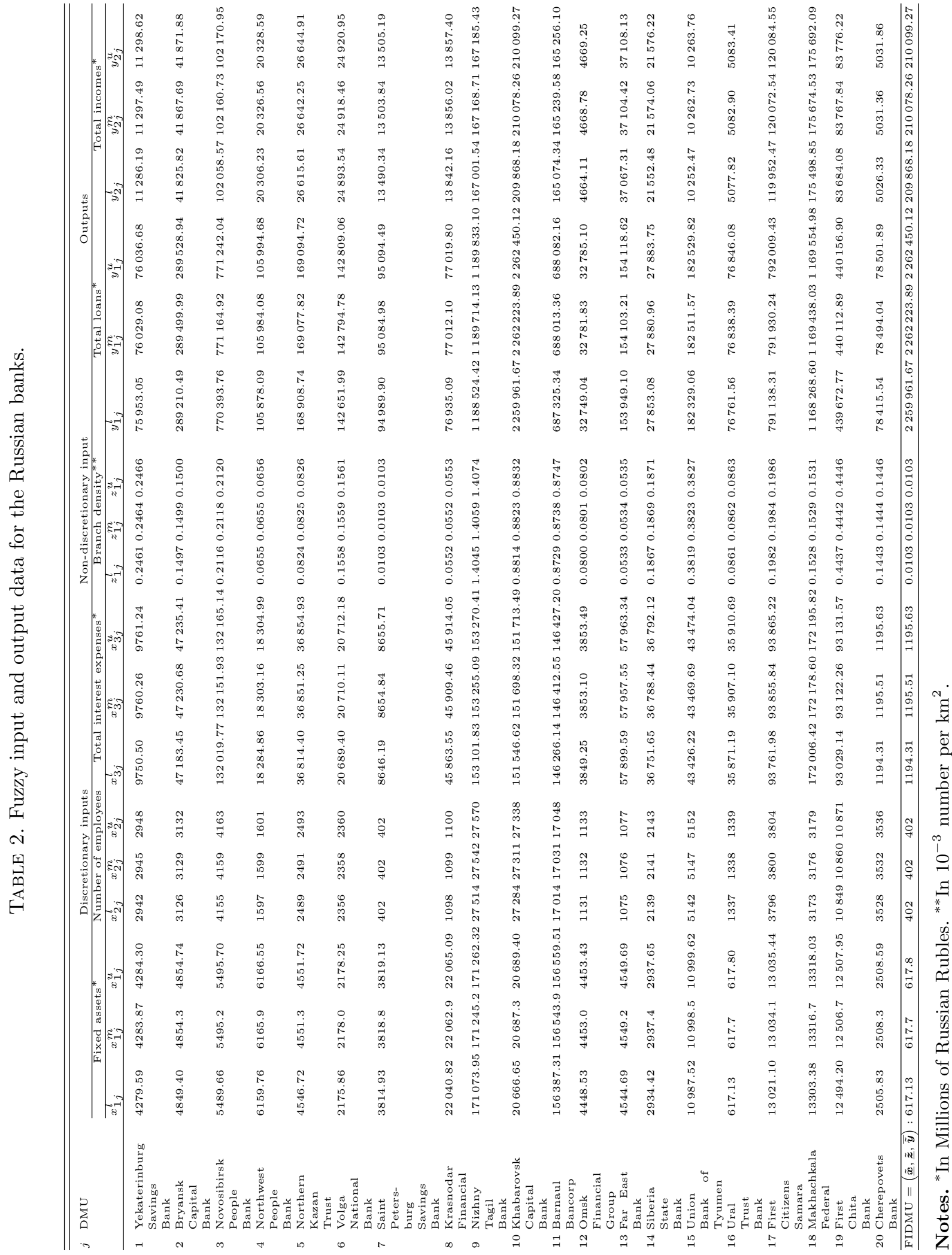


TABLE 3. Normalized efficiency scores and rankings of the Russian banks.

\begin{tabular}{|c|c|c|c|c|c|c|c|c|c|}
\hline \multirow[t]{2}{*}{$j$} & \multirow[t]{2}{*}{$\mathrm{DMU}$} & \multicolumn{8}{|c|}{ Efficiency scores* } \\
\hline & & $\alpha=0.25$ & Rank & $\alpha=0.5$ & Rank & $\alpha=0.75$ & Rank & $\alpha=1$ & Rank \\
\hline 1 & Yekaterinburg Savings Bank & 0.069623 & 18 & 0.069622 & 18 & 0.069621 & 18 & 0.06962 & 18 \\
\hline 2 & Bryansk Capital Bank & 0.243749 & 6 & 0.243748 & 6 & 0.243748 & 6 & 0.243748 & 6 \\
\hline 3 & Novosibirsk People Bank & 0.453649 & 5 & 0.45365 & 5 & 0.453651 & 5 & 0.453652 & 5 \\
\hline 4 & Northwest People Bank & 0.222637 & 7 & 0.222618 & 7 & 0.222599 & 7 & 0.22258 & 7 \\
\hline 5 & Northern Kazan Trust & 0.192283 & 9 & 0.192289 & 9 & 0.192295 & 9 & 0.192302 & 9 \\
\hline 6 & Volga National Bank & 0.187337 & 10 & 0.187341 & 10 & 0.187343 & 10 & 0.187347 & 10 \\
\hline 7 & Saint Petersburg Savings Bank & 0.612904 & 2 & 0.61305 & 2 & 0.613196 & 2 & 0.613342 & 2 \\
\hline 8 & Krasnodar Financial & 0.222145 & 8 & 0.222145 & 8 & 0.222146 & 8 & 0.222146 & 8 \\
\hline 9 & Nizhny Tagil Bank & 0.111105 & 15 & 0.111104 & 15 & 0.111102 & 15 & 0.1111 & 15 \\
\hline 10 & Khabarovsk Capital Bank & 0.152525 & 13 & 0.152527 & 13 & 0.152529 & 13 & 0.152531 & 13 \\
\hline 11 & Barnaul Bancorp & 0.165635 & 11 & 0.165631 & 11 & 0.165626 & 11 & 0.16562 & 11 \\
\hline 12 & Omsk Financial Group & 0.07534 & 17 & 0.075341 & 17 & 0.075343 & 17 & 0.075343 & 17 \\
\hline 13 & Far East Bank & 0.587567 & 3 & 0.58756 & 3 & 0.587552 & 3 & 0.587544 & 3 \\
\hline 14 & Siberia State Bank & 0.159976 & 12 & 0.15997 & 12 & 0.159965 & 12 & 0.159958 & 12 \\
\hline 15 & Union Bank of Tyumen & 0.045352 & 19 & 0.045353 & 19 & 0.045356 & 19 & 0.045358 & 19 \\
\hline 16 & Ural Trust Bank & 0.08212 & 16 & 0.082128 & 16 & 0.082135 & 16 & 0.082143 & 16 \\
\hline 17 & First Citizens Samara & 0.571191 & 4 & 0.571175 & 4 & 0.57116 & 4 & 0.571144 & 4 \\
\hline 18 & Makhachkala Federal & 1 & 1 & 1 & 1 & 1 & 1 & 1 & 1 \\
\hline 19 & First Chita Bank & 0.135226 & 14 & 0.135223 & 14 & 0.13522 & 14 & 0.135216 & 14 \\
\hline 20 & Cherepovets Bank & 0.031122 & 20 & 0.031122 & 20 & 0.031122 & 20 & 0.031121 & 20 \\
\hline
\end{tabular}

Notes. ${ }^{*}$ Normalized efficiency scores are calculated for $\alpha \in(0,1]$ and $\varepsilon=10^{-7}$.

this non-maximum value for epsilon arbitrarily to achieve feasible solutions due to the large values. However, epsilon's optimal value is influential in measuring the weights and producing results with more discriminating power [17].

Table 3 illustrates the normalized efficiency scores of the 20 banks and their ranks for different values of alpha in columns $3-12$. The results demonstrate that all 20 banks are inefficient, and their efficiency values have decreased substantially because of using the CW approach and the ideal point method in efficiency evaluation. This method will consider a virtual ideal unit as the reference object with the lowest inputs and highest outputs. This ideal unit will be considered our ideal efficient DMU with an efficiency score of one [75]. There is a large difference between the efficiency of the ideal unit and all other DMUs.

In the last step, model (3.4) is used to obtain the maximum value of epsilon for model (3.3). Other values greater than $\varepsilon^{*}$ produce infeasible results [82]. Accordingly, the epsilon's optimal values (maximum epsilon) were estimated for $\alpha \in(0,1]$ and applied to recalculate the efficiency scores in the case study, and their value is presented in Table 4. Again, we have normalized the efficiency scores to avoid small efficiencies derived from the implementation of the $\mathrm{CW}$ model and the ideal unit method.

A graphical representation of the recalculated efficiency scores for the optimal epsilon values is presented in Figure 1. The majority of the DMUs have the same rankings for different alpha values due to the adjustments of the weights for achieving optimal answer for $E_{\mathrm{IDMU}}^{*}(\alpha)$ in a $\mathrm{CW}$ model when there is no flexibility for weights.

As shown in Tables 3 and 4, the efficiency scores of the proposed model decrease with the implementation of $\varepsilon^{*}$, and all DMUs obtain different rankings. Also, the efficiency scores in Table 4 follows a different trend. The efficiency scores for the majority of the DMUs decrease with increasing alpha from zero to 0.5 and then follow an increasing trend.

The results in Table 3 show that by using a lower value for the epsilon in model (3.3), the Makhachkala Federal Bank with an efficiency score of 1 is the best DMU even with lower corporate size (around 3170 employees) in 
TABLE 4. Normalized recalculated efficiency scores and rankings of the Russian banks.

\begin{tabular}{|c|c|c|c|c|c|c|c|c|c|}
\hline \multirow[t]{3}{*}{$j$} & \multirow[t]{3}{*}{ DMU } & \multicolumn{8}{|c|}{ Efficiency scores* } \\
\hline & & \multirow{2}{*}{$\begin{array}{l}\alpha=0.25 \\
\varepsilon^{*}=4.047 \times 10\end{array}$} & \multirow[t]{2}{*}{ Rank } & \multirow{2}{*}{$\begin{array}{l}\alpha=0.5 \\
\varepsilon^{*}=4.422 \times 10\end{array}$} & \multirow[t]{2}{*}{ Rank } & \multirow{2}{*}{$\begin{array}{l}\alpha=0.75 \\
\varepsilon^{*}=4.421 \times 10\end{array}$} & \multirow{2}{*}{ Rank } & \multirow{2}{*}{$\begin{array}{l}\alpha=1 \\
\varepsilon^{*}=4.420 \times 10\end{array}$} & \multirow[t]{2}{*}{ Rank } \\
\hline & & & & & & & & & \\
\hline 1 & Yekaterinburg Savings Bank & 0.128967 & 14 & 0.127221 & 13 & 0.127222 & 13 & 0.127222 & 13 \\
\hline 2 & Bryansk Capital Bank & 0.431073 & 7 & 0.426641 & 7 & 0.426641 & 7 & 0.426641 & 7 \\
\hline 3 & Novosibirsk People Bank & 1 & 1 & 1 & 1 & 1 & 1 & 1 & 1 \\
\hline 4 & Northwest People Bank & 0.129593 & 13 & 0.123205 & 14 & 0.123205 & 14 & 0.123206 & 14 \\
\hline 6 & Volga National Bank & 0.486234 & 5 & 0.468991 & 5 & 0.468993 & 5 & 0.468996 & 5 \\
\hline 7 & Saint Petersburg Savings Bank & 0.179926 & 12 & 0.178515 & 12 & 0.178515 & 12 & 0.178515 & 12 \\
\hline 8 & Krasnodar Financial & 0.026062 & 20 & 0.025027 & 20 & 0.025027 & 20 & 0.025027 & 20 \\
\hline 9 & Nizhny Tagil Bank & 0.050153 & 18 & 0.049827 & 18 & 0.049827 & 18 & 0.049827 & 18 \\
\hline 10 & Khabarovsk Capital Bank & 0.755002 & 3 & 0.782661 & 3 & 0.782663 & 3 & 0.782665 & 3 \\
\hline 11 & Barnaul Bancorp & 0.0345 & 19 & 0.031521 & 19 & 0.031521 & 19 & 0.031521 & 19 \\
\hline 12 & Omsk Financial Group & 0.053232 & 17 & 0.052798 & 17 & 0.052798 & 17 & 0.052798 & 17 \\
\hline 13 & Far East Bank & 0.265247 & 9 & 0.242162 & 10 & 0.242163 & 10 & 0.242164 & 10 \\
\hline 15 & Union Bank of Tyumen & 0.110847 & 15 & 0.118905 & 15 & 0.118905 & 15 & 0.118906 & 15 \\
\hline 16 & Ural Trust Bank & 0.827162 & 2 & 0.877927 & 2 & 0.877942 & 2 & 0.877958 & 2 \\
\hline 17 & First Citizens Samara & 0.442172 & 6 & 0.434996 & 6 & 0.434997 & 6 & 0.434998 & 6 \\
\hline 18 & Makhachkala Federal & 0.637418 & 4 & 0.627753 & 4 & 0.627754 & 4 & 0.627756 & 4 \\
\hline 19 & First Chita Bank & 0.264653 & 10 & 0.251886 & 9 & 0.251886 & 9 & 0.251887 & 9 \\
\hline 20 & Cherepovets Bank & 0.210726 & 11 & 0.224387 & 11 & 0.224389 & 11 & 0.22439 & 11 \\
\hline
\end{tabular}

Notes. * Normalized recalculated efficiency scores are obtained with $\alpha \in(0,1]$ and the maximum $\varepsilon$.

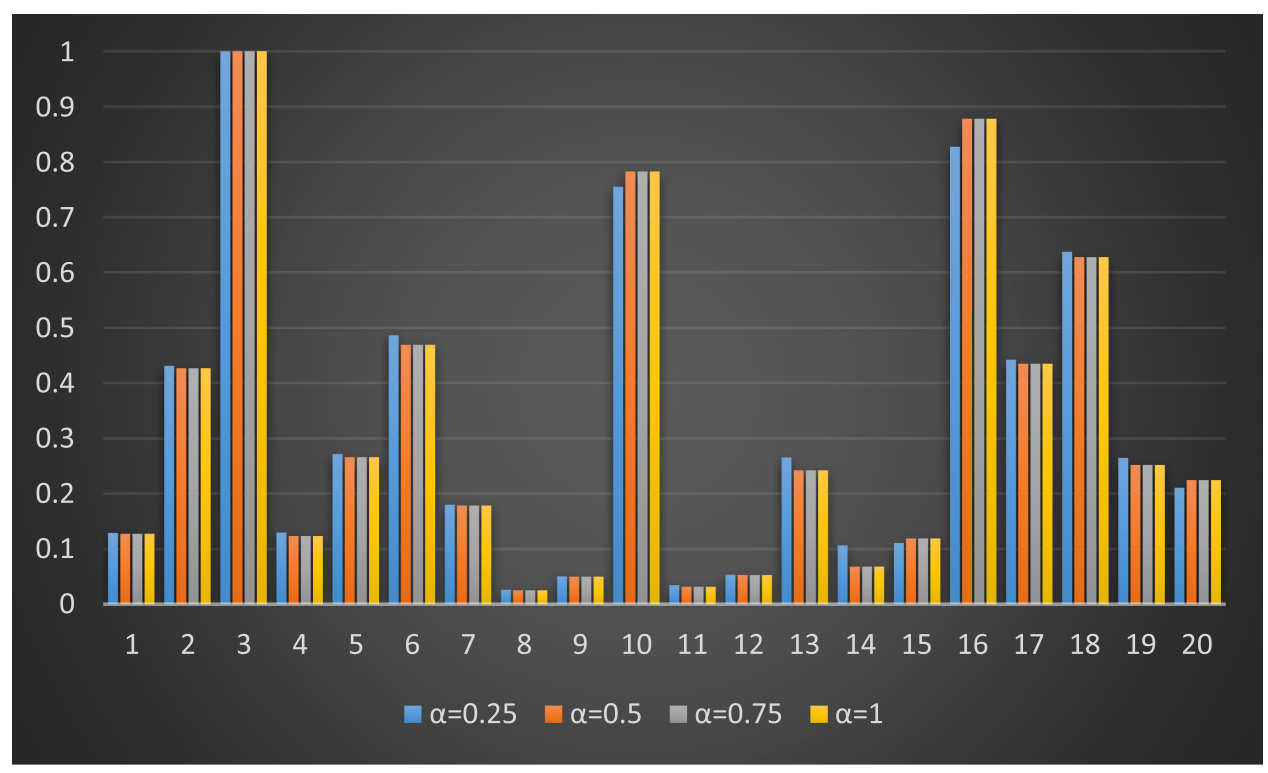

FiguRE 1. Efficiency scores with different alpha levels. 
comparison with Nizhny Tagil Bank (around 27550 employees) and Khabarovsk Capital Bank (around 27300 employees). However, this result is different when we selected $\varepsilon^{*}$ as the optimal value of the epsilon in model (3.3). In this situation, the Novosibirsk People Bank, with an efficiency of 1 has the highest efficiency among the 20 banks. The results demonstrate that focusing on unidimensional and unilateral attributes like the firm size $[23,68]$ is not sufficient for successfully characterizing leaders. Consequently, most literature reviews have concluded that trait theories have fallen out of interest between researchers in the leadership area [38]. We advocate a multilevel, multicomponent, and multidisciplinary approach to leadership $[1,5,51,84]$ for achieving robust and reliable results.

\section{Conclusions And Future Research}

In this paper, we highlighted three shortcomings in the existing DEA models and used non-discretionary inputs and fuzzy data in a CW model with an ideal point method to measure efficiency in the Russian banking industry. We also considered uncertainties inherent in real-world data and used fuzzy sets to take into account these uncertainties. In addition, we considered non-discretionary inputs to incorporate the homogeneity of the DMUs in our model. We used the proposed CW model and ranked 20 independent banks in the Russian Federation. Finally, we used our model to find the efficiency-based leaders in the Russian banking industry. The results show a unidimensional and unilateral assessment of leading organizations merely according to corporate size is not sufficient to effectively characterize industry leaders.

As for further research, we suggest developing a multidimensional DEA model considering different weights for different dimensions. This will allow us to include various characteristics of leadership based on the existent theories in the forms of different dimensions of inputs and outputs.

Declaration of interest. The authors declare no known competing financial interests or personal relationships that could have influenced the work reported in this paper.

Acknowledgements. Dr. Madjid Tavana and Dr. Mehdi Toloo are grateful for the partial support they received from the Czech Science Foundation (GACR19-13946S) for this research. Sajad Kazemi acknowledge the partial support he received from the Saint Petersburg State University for this research (Grant No. 48952577).

\section{REFERENCES}

[1] B.P. Acton, R.J. Foti, R.G. Lord and J.A. Gladfelter, Putting emergence back in leadership emergence: a dynamic, multilevel, process-oriented framework. Leadership Q. 30 (2019) 145-164.

[2] E. Aggelopoulos and A. Georgopoulos, Bank branch efficiency under environmental change: a bootstrap DEA on monthly profit and loss accounting statements of Greek retail branches. Eur. J. Oper. Res. 261 (2017) 1170-1188.

[3] G.R. Amin and M. Toloo, A polynomial-time algorithm for finding epsilon in DEA models. Comput. Oper. Res. 31 (2004) 803-805.

[4] P. Anderson and N.C. Petersen, A procedure for ranking efficient units in data envelopment analysis. Manage. Sci. 39 (1993) 1261-1264.

[5] B.J. Avolio, Promoting more integrative strategies for leadership theory-building. Am. Psychol. 62 (2007) 25-33.

[6] A. Azar, M. Zarei Mahmoudabadi and A. Emrouznejad, A new fuzzy additive model for determining the common set of weights in Data Envelopment Analysis. J. Intell. Fuzzy Syst. 30 (2016) 61-69.

[7] R.D. Banker and R.C. Morey, Efficiency analysis for exogenously fixed inputs and outputs, Eur. J. Oper. Res. 34 (1986) $513-521$.

[8] C.P. Barros and P. Wanke, Banking efficiency in Brazil. J. Int. Financial Markets Inst. Money 28 (2014) 54-65.

[9] B.M. Bass, Bass and Stogdill's Handbook of Leadership. Free Press, New York (1990).

[10] C. Beidleman, Income smoothing: the role of management. Acc. Rev. 48 (1973) 653-667.

[11] H. Bjurek, L. Hjalmarsson and F.R. Førsund, Deterministic parametric and nonparametric estimation of efficiency in service production: a comparison. J. Econ. 46 (1990) 213-227.

[12] A. Charnes, W.W. Cooper and E. Rhodes, Measuring the efficiency of decision-making units. Eur. J. Oper. Res. 2 (1978) $429-444$.

[13] A. Charnes, W.W. Cooper, A.Y. Lewin and L.M. Seiford, Data Envelopment Analysis: Theory Methodology and Applications. Kluwer Academic Publishers, Boston (1994) 1-528.

[14] S.M. Chen, Fuzzy system reliability analysis using fuzzy number arithmetic operations. Fuzzy Sets Syst. 66 (1994) 31-38. 
[15] C.I. Chiang, M.J. Hwang and Y.H. Liu, Determining a common set of weights in a DEA problem using a separation vector. Math. Comput. Model. 54 (2011) 2464-2470.

[16] W.D. Cook, M. Kress and L.M. Seiford, Prioritization models for frontier decision making units in DEA. Eur. J. Oper. Res. 59 (1992) 319-323.

[17] W.D. Cook, M. Kress and L.M. Seiford, Data envelopment analysis in the presence of both quantitative and qualitative factors. J. Oper. Res. Soc. 47 (1996) 945-953.

[18] K. Cullinane and T.-F. Wang, Data envelopment analysis (DEA) and improving container port efficiency. Res. Transp. Econ. 17 (2007) 517-566.

[19] C.C. Defee, T.P. Stank and T.L. Esper, Performance implications of transformational supply chain leadership and followership. Int. J. Phys. Distrib. Logistics Manage. 40 (2010) 763-779.

[20] A. Deville, G.D. Ferrier and H. Leleu, Measuring the performance of hierarchical organizations: an application to bank efficiency at the regional and branch levels. Manage. Acc. Res. 25 (2014) 30-44.

[21] P.J. DiMaggio and W.W. Powell, The iron cage revisited: institutional isomorphism and collective rationality in organizational fields. Am. Soc. Rev. 48 (1983) 147-160.

[22] L. Drake, M.J.B. Hall and R. Simper, The impact of macroeconomic and regulatory factors on bank efficiency: a non-parametric analysis of Hong Kong's banking system. J. Banking Finance 40 (2006) 1443-1466.

[23] E. Esposito and R. Passaro, Evolution of the supply chain in the Italian railway industry. Suppl. Chain Manage. 14 (2009) 303-313.

[24] F.D.S. Fernandes, C. Stasinakis and V. Bardarova, Two-stage DEA-Truncated Regression: application in banking efficiency and financial development. Expert Syst. App. 96 (2018) 284-301.

[25] C. Giachetti and S. Torrisi, Following or running away from the market leader? The influences of environmental uncertainty and market leadership. Eur. Manage. Rev. 15 (2018) 445-463.

[26] R. Gulati and S. Kumar, Analysing banks' intermediation and operating efficiencies using the two-stage network DEA model. Int. J. Prod. Perform. Manage. 66 (2017) 500-516.

[27] A. Hatami-Marbini, A. Emrouznejad and M. Tavana, A taxonomy and review of the fuzzy data envelopment analysis literature: two decades in the making. Eur. J. Oper. Res. 214 (2011) 457-472.

[28] A. Hatami-Marbini, M. Tavana, P.J. Agrell, L.F. Hosseinzadeh and Z. Ghelej Beigi, A common-weights DEA model for centralized resource reduction and target setting. Comput. Ind. Eng. 79 (2015) 195-203.

[29] P. Haunschild and A. Miner, Modes of interorganizational imitation: the effects of outcome salience and uncertainty. Admin. Sci. Q. 42 (1997) 472-500.

[30] N. Hiller, L. DeChurch, T. Murase and D. Doty, Searching for outcomes of leadership: a 25-year review. J. Manage. 37 (2011) $1137-1177$.

[31] D. Holod and H.F. Lewis, Resolving the deposit dilemma: a new DEA bank efficiency model. J. Banking Finance 35 (2011) 2801-2810.

[32] H.-C. Hsiao, H. Chang, A.M. Cianci and L.-H. Huang, First financial restructuring and operating efficiency: evidence from Taiwanese commercial banks. J. Banking Finance 34 (2010) 1461-1471.

[33] Z.S. Hua, Y.W. Bian and L. Liang, Eco-efficiency analysis of paper mills along the Huai River: an extended DEA approach. Omega 35 (2007) 578-587.

[34] T.-H. Huang, K.-C. Chen and C.-I. Lin, An extension from network DEA to Copula-based network SFA: evidence from the U.S. commercial banks in 2009. Q. Rev. Econ. Finance 67 (2018) 51-62.

[35] J.-M. Huguenin, Data Envelopment Analysis and non-discretionary inputs: How to select the most suitable model using multi-criteria decision analysis. Expert Syst. App. 42 (2015) 2570-2581.

[36] G.R. Jahanshahloo, H.V. Junior, F.H. Lotfi and D. Akbarian, A new DEA ranking system based on changing the reference set. Eur. J. Oper. Res. 181 (2007) 331-337.

[37] G.R. Jahanshahloo, F. HosseinzadehLotfi, M. Khanmohammadi, M. Kazemimanesh and V. Rezaie, Ranking of units by positive ideal DMU with common weights. Expert Syst. App. 37 (2010) 7483-7488.

[38] T.A. Judge, J.E. Bono, R. Ilies, M.W. Gerhardt, Personality and leadership: A qualitative and quantitative review. J. Appl. Psychol. 87 (2002) 765-780.

[39] M. Kadziński, A. Labijak and M. Napieraj, Integrated framework for robustness analysis using ratio-based efficiency model with application to evaluation of Polish airports. Omega 67 (2017) 1-18.

[40] S. Kaffash, R.K. Matin and M. Tajik, A directional semi-oriented radial DEA measure: an application on financial stability and the efficiency of banks. Ann. Oper. Res. 264 (2018) 213-234.

[41] F. Kamarudin, F. Sufian, F.W. Loong and N.A.M. Anwar, Assessing the domestic and foreign Islamic banks efficiency: insights from selected Southeast Asian countries. Future Bus. J. 3 (2017) 33-46.

[42] C. Kao and H.T. Hung, Data envelopment analysis with common weights: the compromise solution approach. J. Oper. Res. Soc. 56 (2005) 1196-1203.

[43] D.J. Ketchen, J. Charles, C. Snow and V.L. Hoover, Research on competitive dynamics: recent accomplishments and future challenges. J. Manage. 30 (2004) 779-804.

[44] R. Kiani Mavi, S. Kazemi and J.M. Jahangiri, Developing common set of weights with considering nondiscretionary inputs and using ideal point method. J. Appl. Math. 2013 (2013) 1-9.

[45] G. Lanine and R.V. Vennet, Failure prediction in the Russian bank sector with logit and trait recognition models. Expert Syst. App. 30 (2006) 463-478. 
[46] A.E. LaPlante and J.C. Paradi, Evaluation of bank branch growth potential using data envelopment analysis. Omega 52 (2015) $33-41$.

[47] H. Li, C. Chen, W.D. Cook, J. Zhang and J. Zhu, Two-stage network DEA: Who is the leader? Omega 74 (2018) 15-19.

[48] M.B. Lieberman and S. Asaba, Why do firms imitate each other? Acad. Manage. Rev. 31 (2006) 366-385.

[49] M.B. Lieberman and D.B. Montgomery, First-mover advantages. Strategic Manage. J. 9 (1988) 41-58.

[50] F.-H.F. Liu and H.H. Peng, Ranking of units on the DEA frontier with common weights. Comput. Oper. Res. 35 (2008) $1624-1637$.

[51] R.G. Lord, D.V. Day, S.J. Zaccaro, B.J. Avolio and A.H. Eagly, Leadership in applied psychology: three waves of theory and research. J. Appl. Psychol. 102 (2017) 434-451.

[52] A. Lozano-Vivas, J.T. Pastor and J.M. Pastor, An efficiency comparison of European banking systems operating under different environmental conditions. J. Prod. Anal. 18 (2002) 59-77.

[53] A.W. Mackelprang, E. Bernardes, G.J. Burke and C. Welter, Supplier innovation strategy and performance: a matter of supply chain market positioning. Decis. Sci. 49 (2018) 660-689.

[54] M. Mamonov and A. Vernikov, Bank ownership and cost efficiency: new empirical evidence from Russia. Econ. Syst. 41 (2017) 305-319.

[55] K. Matthews, Risk management and managerial efficiency in Chinese banks: a network DEA framework. Omega 41 (2013) $207-215$.

[56] M.S. Mizruchi and L.C. Fein, The social construction of organizational knowledge: a study of the uses of coercive, mimetic, and normative isomorphism. Admin. Sci. Q. 44 (1999) 653-683.

[57] O.B. Olesen and N.C. Petersen, Stochastic data envelopment analysis: a review. Eur. J. Oper. Res. 251 (2016) $2-21$.

[58] J. Ouenniche and S. Carrales, Assessing efficiency profiles of UK commercial banks: a DEA analysis with regression-based feedback. Ann. Oper. Res. 266 (2018) 551-587.

[59] J.C. Paradi, and H. Zhu, A survey on bank branch efficiency and performance research with data envelopment analysis. Omega 41 (2013) 61-79.

[60] A. Payan, Common set of weights approach in fuzzy DEA with an application. J. Intel. Fuzzy Syst. 29 (2015) $187-194$.

[61] M.E. Porter, Competitive Strategy: Techniques for Analyzing Industries and Competitors. Free Press, New York (1980).

[62] J. Puri and S.P. Yadav, A fuzzy DEA model with undesirable fuzzy outputs and its application to the banking sector in India. Expert Syst. App. 41 (2014) 6419-6432.

[63] J. Ruggiero, On the measurement of technical efficiency in the public sector. Eur. J. Oper. Res. 90 (1996) 553-565.

[64] J. Ruggiero, Nondiscretionary inputs in data envelopment analysis. Eur. J. Oper. Res. 111 (1998) 461-469.

[65] S. Saati, A. Memariani and G.R. Jahanshahloo, Efficiency analysis and ranking of DMUs with fuzzy data. Fuzzy Optim. Decis. Making 1 (2002) 255-267.

[66] S. Saati, A. Hatami-Marbini, J. Per, P.J. Agrell and M. Tavana, A common set of weight approach using an ideal decisionmaking unit in data envelopment analysis. J. Ind. Manage. Optim. 8 (2012) 623-637.

[67] M. Salahi and M. Toloo, In the determination of the most efficient decision making unit in data envelopment analysis: a comment. Comput. Ind. Eng. 104 (2017) 216-218.

[68] N.R. Sanders, IT alignment in supply chain relationships: a study of supplier benefits. J. Suppl. Chain Manage. 41 (2005) $4-13$.

[69] J. Shyu and T. Chiang, Measuring the true managerial efficiency of bank branches in Taiwan: a three-stage DEA analysis. Expert Syst. Appl. 39 (2012) 11494-11502.

[70] T.C. Silva, B.M. Tabak, D.O. Cajueiro and M.V.B. Dias, A comparison of DEA and SFA using micro- and macro-level perspectives: efficiency of Chinese local banks. Phys. A: Stat. Mech. App. 469 (2017) 216-223.

[71] Z. Svitalkova, Comparison and evaluation of bank efficiency in selected countries in EU. Proc. Econ. Finance 12 (2014) 644-653.

[72] K.G. Smith, W.J. Ferrier and C.M. Grimm, King of the hill: dethroning the industry leader. Acad. Manage. Executive 15 (2001) 59-70.

[73] M. Soleimani-Damaneh, G.R. Jahanshahloo and S. Abbasbandy, Computational and theoretical pitfalls in some current performance measurement techniques and a new approach. Appl. Math. Comput. 181 (2006) 1199-1207.

[74] C. Staikouras, E. Mamatzakis and A. Koutsomanoli-Filippaki, Cost efficiency of the banking industry in the South Eastern European region. J. Int. Financial Markets Inst. Money 18 (2008) 483-497.

[75] J. Sun, J. Wu and D. Guo, Performance ranking of units considering ideal and anti-ideal DMU with common weights. App. Math. Model. 37 (2013) 6301-6310.

[76] M. Tavana, S. Kazemi and R. Kiani Mavi, A stochastic data envelopment analysis model using a common set of weights and the ideal point concept. Int. J. Appl. Manage. Sci. 7 (2015) 81-92.

[77] M. Tavana, K. Khalili-Damghani, F.J. Santos Arteaga, R. Mahmoudi and A. Hafezalkotob, Efficiency decomposition and measurement in two-stage fuzzy DEA models using a bargaining game approach. Comput. Ind. Eng. 118 (2018) $394-408$.

[78] M. Toloo, Selecting and full ranking suppliers with imprecise data: a new DEA method. Int. J. Adv. Manuf. Technol. 74 (2014) 1141-1148.

[79] M. Toloo, Alternative minimax model for finding the most efficient unit in data envelopment analysis. Comput. Ind. Eng. 81 $186-194$.

[80] M. Toloo and T. Ertay, The most cost efficient automotive vendor with price uncertainty: a new DEA approach. Measurement 52 (2014) 135-144. 
[81] M. Toloo and A. Kresta, Finding the best asset financing alternative: a DEA-WEO approach. Measurement 55 (2014) $288-294$.

[82] M. Toloo and M. Salahi, A powerful discriminative approach for selecting the most efficient unit in DEA. Comput. Ind. Eng. 115 (2018) 269-277.

[83] M. Toloo and T. Tichy, Two alternative approaches for selecting performance measures in data envelopment analysis. Measurement 65 (2015) 29-40.

[84] M. Uhl-Bien, R. Marion and B. McKelvey, Complexity leadership theory: shifting leadership from the industrial age to the knowledge era. Leadership Q. 18 (2007) 298-318.

[85] M.I.M. Wahab, D. Wu and C.-G. Lee, A generic approach to measuring the machine flexibility of manufacturing systems. Eur. J. Oper. Res. 186 (2008) 137-149.

[86] Y.M. Wang, Y. Luo and Y.X. Lan, Common weights for fully ranking decision-making units by regression analysis. Expert Syst. App. 38 (2011) 9122-9128.

[87] W.-K. Wang, W.-M. Lu and P.-Y. Liu, A fuzzy multi-objective two-stage DEA model for evaluating the performance of US bank holding companies. Expert Syst. App. 41 (2014) 4290-4297.

[88] K. Wang, W. Huang, J. Wu, Y.N. Liu, Efficiency measures of the Chinese commercial banking system using an additive two-stage DEA. Omega 44 (2014) 5-20.

[89] P. Wanke and C. Barros, Two-stage DEA: an application to major Brazilian banks. Expert Syst. App. 41 (2014) $2337-2344$.

[90] P. Wanke, C.P. Barros and A. Emrouznejad, Assessing productive efficiency of banks using integrated fuzzy-DEA and bootstrapping: a case of Mozambican Banks. Eur. J. Oper. Res. 249 (2016) 378-389.

[91] J. Wu, L. Liang and M. Song, Performance based clustering for benchmarking of container ports: an application of DEA and cluster analysis technique. Int. J. Comput. Intel. Syst. 3 (2010) 709-722.

[92] G.A. Yukl, Leadership in Organizations. Prentice Hall, Englewood Cliffs, NJ (2001).

[93] L.A. Zadeh, Fuzzy sets. Inf. Control 8 (1965) 338-353.

[94] L.M. Zerafat Angiz, A. Emrouznejad, A. Mustafa and A.S. Al-Eraqi, Aggregating preference ranking with fuzzy data envelopment analysis. Knowl.-Based Syst. 23 (2010) 512-519.

[95] J. Zhang, C. Jiang, B. Qu and P. Wang, Market concentration risk-taking and bank performance: evidence from emerging economies International. Rev. Financial Anal. 30 (2013) 149-157.

[96] H. Zhao and S. Kang, Banking Performance Evaluation in China based on non-radial super-efficiency data envelopment analysis. Procedia Economics and Finance 23 (2015) 197-202.

[97] X. Zhou, R. Luo, Y. Tu, B. Lev and W. Pedrycz, Data envelopment analysis for bi-level systems with multiple followers. Omega $\mathbf{7 7}(2018)$ 180-188.

[98] X. Zhou, Z. Xu, J. Chai, L. Yao, S. Wang and B. Lev, Efficiency evaluation for banking systems under uncertainty: a multiperiod three-stage DEA model. Omega 85 (2019) 68-82.

[99] W. Zhu, Y. Yu and P. Sun, Data envelopment analysis cross-like efficiency model for non-homogeneous decision-making units: the case of United States companies' low-carbon investment to attain corporate sustainability. Eur. J. Oper. Res. 269 (2018) 99-110. 